\title{
Dependable estimations for education quality using fuzzy logic based strategy a case study (University of Kufa)
}

\author{
Adel Al-Janabi, Ehsan Ali Al-Zubaidi, Radhwan Hussein Abdulzhraa Al Sagheer \\ University of Kufa, Iraq
}

\begin{tabular}{l}
\hline \hline Article Info \\
\hline Article history: \\
Received Jun 20, 2019 \\
Revised Jul 17, 2019 \\
Accepted Aug 10, 2019 \\
\hline
\end{tabular}

\section{Keywords:}

AHP

Education service

Fuzzy Sets Theory

Performance

Student satisfaction

\begin{abstract}
The consideration that the Iraqi community has concentrated on the training area has delivered another college responsibility routed to superiority viewpoints for all training connected facilities. In truth, a superiority arranged facility necessitates perfection in the structure and arranging of facility exercises, in addition to amid its conveying for the received facility execution assessment strategy. In any case, considering that facility execution assessments are profoundly founded on partners' decisions, they can be described by conceivable vulnerabilities identified with deficiency for incomplete obliviousness, imprecision for subjectivity and even dubiousness. In this way, underneath these circumstances, temperamental outcomes can be acquired by broadly measured facility investigation strategies. This paper is a strategy dependent an ongoing augmentation of ServQual display and it utilizes a consolidated way of Fuzzy Set Theory of command process technique that is proposed to adequately deal with vulnerability in facility execution examinations. Specifically, Fuzzy Set Theory is measured to manage vulnerability, while AHP strategy is embraced as device to appraise the significance loads of key facility characteristics. In this way, the key investigation of the facility esteem tree identified with the program in University of Kufa is made by using the planned strategy. The completed facility examination permits the most impacting facility execution components to be caught and remarked. At last, acquired outcomes demonstrate that the teachers' view of facility quality definitively impacts by large facility execution level.
\end{abstract}

Copyright $@ 2020$ Institute of Advanced Engineering and Science. All rights reserved.

\section{Corresponding Author:}

Ehsan Ali Al-Zubaidi,

Department of Envorimental Planning,

University of Kufa, Iraq.

Email: ihsana.kareem@uokufa.edu.iq

\section{INTRODUCTION}

Quality is a word usually considered to demonstrate a great dimension of client's fulfillment by alludes to feature portray thought about item or facility. Specifically, as training facilities, the linked quality idea emerging of perspectives and educating highlights, inquire connected exercises, with alluding to them ability to fulfill unequivocally set out goals. Since the Iraqi advanced education is characterized by neighborhood pronounced level in every University in its services. In this manner, a "quality University" is that one that ensures to all partners, basically undergraduates, convicting about the ability to get appropriate outcomes as for expressed and guaranteed destinations [1]. Thus, it is fundamental that nature of instruction services is ceaselessly observed and constrained by appropriate observing systems. The execution of solid service assessments can be a troublesome issue to deal with, since services are portrayed by some critical parts of intricacy identified with their unconventional attributes [2]. Services are commonly viewed as: Intangible, for example inconsequential; Indivisible, for example services are created, conveyed and devoured at the same time; Heterogeneous, for example a service gave to one client that is not precisely 
equivalent; Transitory, for example services cannot be created ahead of time and put away for later conveyance [3]. Sharing item, for example clients of a facility are likewise facility producers, the accomplished facility execution straightforwardly impacts them in the essence and connection amid facility conveying [4].

Services are not controllable and in this way likewise quantifiable in their own specialized and business particulars in quantitative terms by established estimating systems as well as to the regular measure units. Suggestions to the last angles include the requirement for structure appropriate procedures for solid service execution assessments, in addition to distinguish "a typical" amount items, whenever contrasted when persons are utilized in assembling field, to feature the accomplished facility execution plane [5].

Facility execution is "unphysical amount" that tells an idle quality of the service. It cannot legitimately be estimated, for example its assessment is finished thinking about quantifiable and reasonable service qualities which execution levels give about proportion of service execution. For instance, the assessment of consumer loyalty speaks to proportion of the service execution plane, meanwhile it is accomplished in connection to legitimate facility perspectives whose execution planes are measured by methods for supposed "show factors," that are expected as "dormant appearances" of Service execution. The connection between show factors and idle indications can be formalized by methods for explicit calculated models [6]. During writing, a few theoretical ideals are defined between established principles that are recorded:

a) ServQual, whose hypothetical standard is error or hole hypothesis: distinction among facility recognitions and desires, significance weight doled out to each facility measurement;

b) Two-Way, in light of the thought that the inactive variables are of impartial (superiority characteristics) and "emotional" (fulfillment stages) type;

c) SERVPERF, in facility recognitions that show factors of the service execution;

d) Normed Quality, whose hypothetical guideline accept that a qualification among perfect and achievable desires must be done so as to assess the service execution;

e) Qualitometro, as indicated by which the discernments and desires measures must be performed at various occasions.

Notwithstanding, those recently thought to be, other applied models have been proposed centered around tasks viewpoints related to support conveying and on unwavering quality service, for example its ability to convey what the client needs [7]. To date the ServQual demonstrates a standout amongst the most set up applied models for deciding consumer loyalty in services. ServQual display is used widely in writing facility; a few later utilizations ServQual display in various facility parks are depicted: The SERVQUAL display in its unique plan comprises of 22 proclamations estimating 5 basic to quality components of service quality in particular substantial quality, dependability, responsiveness, affirmation, what's more, sympathy. The required information appraisal of facility superiority in environment which can be communicated regarding definite statistics through etymological arithmetical assessment measures. Additionally, in facility superiority idea (7) significant Holes are measured by the writers.

As indicated by an ongoing advancement of the ServQual display, the three principle Holes, which are additional connected with consumer loyalty are: Hole 1, Hole 5furthermore, Hole 6; meanwhile they have an immediate association with clients. Such Holes quantity the inconsistency among:

a) clients' desires and the executives' view of facility superiority, for Hole 1 ;

b) clients' desires and representatives' impression of facility superiority, for Hole 6;

c) clients' desires and observations, for Hole 5.

Furthermore, they are assessed with connection to basic superiority facility principles and subprinciples .Through thinking about the intellectual circle of partner, such facility Holes esteems can got the logarithmic correlation among [8]:

a) the board's impression of the clients' desires (PM)also, the clients' desires(E): Hole1 $=\mathrm{P}_{\mathrm{M}}-\mathrm{E}$;

b) workers' impression of clients' desires (PE) and clients' desires (E): Hole6 $=P_{E}-E$;

c) clients' recognitions $(\mathrm{P})$ and desires $(\mathrm{E})$ : Hole5 $=\mathrm{P}-\mathrm{E}$.

In this way, principles accepted in Hole 1 can be considered as a straight consequence of absence of promoting study introduction and insufficient ascending correspondence, though Hole 6 esteems informs the consequence of distinctions in comprehension of client desires by bleeding edge specialist co-ops. Hole 5 esteems mirror the after effect of the impacts applied from the client side deficits (Holes) with respect to the specialist organization and accordingly such qualities can be considered as immediate pointers of the consumer loyalty degree. Along these lines, clients' disappointment is gathered facility perspectives in which undesirable estimation of the Hole 5 is acquired [9].

The assumed economic relation and asset requirements, just expanded the challenge between scholarly associations with respect to understudy enlistment, seeing precisely what understudies expect is the most urgent advance in characterizing and conveying superb training service. Specifically, it is key that 
students' desires and discernments are appropriately estimated and effectively comprehended and that, from the point of view of understudies, basic to superiority facility principles and sub-principles are appropriately recognized. Indeed, the last amount sought to be taken into the plan procedure to successfully bolster the leader in distinguishing reasonable "Holes arranged" service improvement arrangements [10] .

Numerous basic components are related to the work of ServQual display. A few troubles are identified with the utilization of semantic assessment scales: the all-around recorded inclination of respondents to choose focal semantic classes to express decisions' impact of the semantic classes amount in assessment method, structure and sort of embraced semantic factors and the change since prime to metric in formation. Further, basic components are identified with uncertainty of desires assessment and the troubles emerging from utilization of difference psychometric notch [7] .

In the past contemplations, ServQual inconsistency worldview is considered to assess learner fulfillment plane. Nonetheless, assessing facility desires 'planes are essential by the ServQual demonstrating that the Analytic Hierarchy Procedure (AHP) strategy is measured. AHP is a multi-principles basic leadership strategy that assistances leader confronting an unpredictable issue with numerous clashing, abstract criteria (e.g., area or speculation choice, ventures positioning, etc). AHP depends on three standards that decide the system ventures of the technique [11]: the rule of issue progressive disintegration; the rule of examination decisions and the rule of the blend are considered to total incomplete outcomes so as to get the worldwide outcome. Consequently, the strategy comprises of the accompanying stages: distinguishing proof of the general goal of the examination and various leveled deteriorations of the issue; development of pair wise correlations frameworks; assessment of neighborhood significance loads lastly, assurance of the worldwide significance loads [12]. AHP presents a few favorable circumstances such as full separation among significance evaluations, looking for consistency indecisions by methods for the inconsistency ratio IR, effectiveness to use, and so on. It likewise permits to structure complex issues in the structure of an order or a lot of incorporated dimensions and that can be joined with tasks inquire those methods to deal with progressively trouble some issues. A few papers have ordered the AHP examples of overcoming adversity in altogether dissimilar fields. In Assignment the board field, AHP takes utilized appraisal and designation of people propose fuzzy choice creation scheme assessment of undertaking the executives inward productivity through bearing in mind as assessment principles venture price, venture period and undertaking superiority and they recommend the utilization of AHP to discover the overall loads of principles. Proposing utilization of AHP in the field undertakes the board [13] outlines the different designing fields in which AHP has been as of late connected. Despite what might be expected, in facility superiority appraisal,. For instance, AHP is proposed to discover the relative significance loads of vital facility qualities open travel service area. So as to receive the AHP strategy present work, the initial stage fears the recognizable proof of the progressive construction of facility superiority. The last comprises of a few various levels: the first incorporates the general goal or objective of the examination, for example in general learner fulfillment. In another dimension, facility superiority principle, for example, is accounted for facility principle qualities that are profoundly connected with learner fulfillment. Along these lines, in third dimension facility sub-principles for every facility foundation are recognized. At last, in fourth dimension, the facility things for every facility sub-model are measured. These fulfillment measurements ought to guarantee a predictable private of principles, with the accompanying possessions: (1) monotonicity, (2) comprehensiveness, and (3) non-glut proposed likewise that the arrangement of criteria; furthermore, the planned esteem pecking order ought to be operational, decomposable negligible demonstrates a general various leveled superiority construction formed by superiority principles, $\mathrm{C} 1 ; \mathrm{C} 2 ; \ldots$; everyone is formed by $\mathrm{C} 1 ; \mathrm{C} 2 ; \ldots$; facility sub-principles. Specifically, the conventional facility sub-principles $\mathrm{j}$ of the facility model I is indicated by the period SCij.

However, the AHP technique in its unique deterministic definition can be questionable in taking care of vagueness of the ideas related by the utilization of the humanoid learning. Meanwhile, humanoid learning to definite decisions and inclinations are all the time inadequate, conflicting and even ambiguous or uncertain, as outcome, people cannot have the capacity to express, with reasonable unwavering quality dimension, their feeling by methods for an accurate numerical esteem identified with a phonetic flexible, essential in unique detailingby AHP [14]. This circumstance can present vulnerability in facility execution examinations. The decision of the method to be utilized to limit vulnerability impacts is normally in light of the sort and nature of vulnerability. Specifically, [15] brought up vulnerability classes and the related ways to deal with be embraced to manage them. Vulnerability identified with service execution examinations is of epistemic type: it is for the most part attributed to the concurrence of three significant viewpoints in partners' decisions: dubiousness, trademark that shows the need or inadequate learning with connection to an article or a data; imprecision, trademark that is alluded to the blend of at least two data segments. In this way, this paper the Fuzzy Set Theory (FST) is measured to manage very vulnerability kind [16, 17].

The creative commitments that originated from the utilization of the FST are got from its ability of portrayal and handling of data influenced by some flaw regularly because of the utilization of the regular 
language, the FST permits the scientific portrayal of unsure information; furthermore, it gives formalized apparatuses to managing natural imprecision of genuine issues. It is especially helpful in the measurement of phonetic classes since it permits the portrayal for various" participation degrees" of an idea. This element is very much spoken to by the thought communicated by [8] (FST) register per arguments, which features necessity for a powerful boundary among the statistics fresh domain and semantic classifications so as to improve the comprehension and usage capacity of genuine data. The emotional assessment information can be communicated by etymological factors. The FST has been connected in numerous fields of the service science; however, it is still unobtrusively utilized in the field of the service quality evaluation . The reason for current effort is suggesting a dependable technique dependent ongoing improvement ServQual typical to assess training facility fundamental Holes esteems expecting to defeat the recently portrayed impediments. A proficient joined strategy in light of reconciliation among AHP technique and FST is planned to adequately deal with epistemic vulnerability in facility execution examinations [18, 19]. In this way, the key investigation of instruction service identified at University of Kufa (Iraq) and is achieved by utilizing the planned technique .

\section{DESIGN AND METHODOLOGY}

This section contains a concise diagram around FST; hypothetical standards that are helpful to current work are also assumed. In this manner, reflected methodology is aimed at estimation of scholastic partners' significance loads and recognition dimensions of facility principles and sub-principles are depicted .

\subsection{Fuzzy Set Theory and lingual Fuzzy Measures}

Knowledge of convex established varies after connecting the established set hypothesis: fuzzyset said arched while enrollment level $\mu_{A}$ of a component $\mathrm{x}_{2}$ between two components $\mathrm{x}_{1}$ and $\mathrm{x}_{3}$ isn't not exactly the base an incentive among the enrollment degrees of $\mathrm{x} 1$ and $\mathrm{x} 3$. At that point, fuzzy quantity $\tilde{A}$ is a curved fuzzy characterized until $\mathrm{R}$ and by the end so that:

a) $\exists \mathrm{x} 0 \mid \mu \mathrm{A}(\mathrm{x} 0)=1$

b) The belonging task $\mu_{\mathrm{A}}(\mathrm{x})$ procedding.

The last property is important to legitimately speak to reflected originations. Specifically, overall rule fuzzy evaluation method a phonetic mutable can be seen as a factor whose qualities are arguments whose significance is characterized by guidance tenets. Etymological changeable is described by 5 components $\left(\mathrm{X}, \mathrm{T}_{(\mathrm{X})}, \mathrm{U}, \mathrm{G}, \mathrm{M}\right)$ where: $\mathrm{X}$ is the term of the changeable; , $\mathrm{T}_{\mathrm{X})}$ is arrangement etymological classifications of the inconstant, $\mathrm{U}$ is world of talk, $\mathrm{G}$ is an analytic decision produces the relations in $\mathrm{T}_{(\mathrm{X})}$ and $\mathrm{M}$ semantics guideline partners every phonetic class $\mathrm{x}$ of $\mathrm{T}_{(\mathrm{X})}$ its importanceM(x). Such semantics guideline might be characterized by a fuzzy quantity $\mathrm{M}(\mathrm{x})$ in $U$. Along these lines, significance $\mathrm{M}(\mathrm{x})$ of phonetic class $\mathrm{x}$ is characterized thru participation work $\mu_{\mathrm{x}}: \mathrm{U} \rightarrow[0,1]$ partners to every $\mathrm{U}$ similarity by $\mathrm{x}[8]$.

A optimistic deltoid fuzzynumber (TFN), indicated $\tilde{A}=\left(x_{L}, x_{M}, x_{U}\right)$ where $x_{L} \leq x_{M} \leq x_{U}$, has the accompanying triangular-type membership function:

$$
\mu_{\mathrm{A}}(\mathrm{x})=\left\{\begin{array}{cc}
\frac{x-x_{L}}{x_{M}-x_{L}} & \text { for } x_{L} \leq \mathrm{x} \leq x_{M} \\
\frac{x-x_{U}}{x_{U}-x_{M}} & \text { for } x_{M} \leq \mathrm{x} \leq x_{U} \\
0 & \text { otherwise }
\end{array}\right.
$$

Then again, by characterizing the interim of certainty level an ( $\alpha$-cut), aTFN can be described as :

$$
\begin{aligned}
& \forall \alpha \in[0,1] \\
& \tilde{\mathrm{A}} \alpha=\left[\alpha_{L}^{\alpha}, \alpha_{U}^{\alpha}\right]=\left[\left(\mathrm{x}_{\mathrm{M}}-\mathrm{x}_{\mathrm{L}}\right) \alpha+\mathrm{x}_{\mathrm{L}},-\left(\mathrm{x}_{\mathrm{U}}-\mathrm{x}_{\mathrm{M}}\right) \alpha+\mathrm{x}_{\mathrm{U}}\right]
\end{aligned}
$$

Service execution investigations frequently articulate partners' information /decisions in word of linguistics variable; the utilization TFN as approach to think about unsure decisions proposed also, generally embraced into later work. It gave an outline to characterize the lower and upper limit for such semantic factors dependent on specialists 'appraisal. Considering the no doubt an incentive as normal limits, TFN is able to utilize to speak semantic factors. Unsure limits TFN can likewise characterized by methods for Fuzzy strategy run of the characteristic multi-specialists process joining ideas $[4,20]$.

The FST permits the expansion of number juggling activities from fresh number fuzzy number. Thinking about participation gradation $\alpha(\alpha-$ cut $)$ progressive crisp number, principle tasks processes point of articulations : 


$$
\begin{aligned}
& \forall \alpha \in[0,1], \forall a_{L}, a_{U}, b_{L}, b_{U} \in R^{+}, A_{\alpha}=\left[a_{L}^{\alpha}, a_{U}^{\alpha}\right], B_{\alpha}=\left[b_{L}^{\alpha}, b_{U}^{\alpha}\right] \\
& A_{\alpha} \Theta B_{b}=\left[a_{L}^{\alpha}-b_{L}^{\alpha}, a_{U}^{\alpha}-b_{U}^{\alpha}\right] \\
& A_{\alpha} \oplus B_{b}=\left[a_{L}^{\alpha}+b_{L}^{\alpha}, a_{U}^{\alpha}+b_{U}^{\alpha}\right] \\
& A_{\alpha} / B_{b}=\left[a_{L}^{\alpha} / b_{L}^{\alpha}, a_{U}^{\alpha} / b_{U}^{\alpha}\right] \\
& A_{\alpha} \otimes B_{b}=\left[a_{L}^{\alpha} \times b_{L}^{\alpha}, a_{U}^{\alpha} \times b_{U}^{\alpha}\right]
\end{aligned}
$$

In the present investigation, etymological factors are utilized to speak topartners' appraisals as well as TFN are measuredthem assessments.

\subsection{Estimation of partners' desires}

As stated, fuzzy augmentations of AHP technique (AHP) is measured to adequately deal with vulnerability identified with the estimation of partners' decisions. AHP has been broadly embraced at whatever point people cannot utilize an accurate numerical incentive to definite conclusion besides phonetic mutable that is utilized to particular arithmetical esteem. Regularly, legitimate phonetic mutable is made a clarification equivocalness as well as ambiguity related by area of issue [21]. Subsequently, idea phonetic articulation is measured by fuzzy number utilizing a legitimate enrollment work. A few late utilizations, AHP methodology in various fields is portrayed [22]. The AHP method is hardly utilized in facility superiority appraisal. The four stage systems of methodology

Step 1: Collate the execution.

Etymological expressions are utilized to show the overall significance both couple of components into a similar chain of command level and TFNs are considered to measure ideas of etymological articulations .Since the facility sub-principles of the nonexclusive facility rule $k$, $\tilde{a}_{\mathrm{ij}}$ are indicated the fuzzy structure, component I required to component $\mathrm{j}$, by way of connection to the facility measure $\mathrm{k}$. That the components number to be looked at is equivalent to $\mathrm{C}_{\mathrm{k}}$, at that point it is important to express $C_{k}^{2}$ pairwise correlations. Just $\mathrm{C}_{\mathrm{k}}\left(\mathrm{C}_{\mathrm{k}}-1\right) / 2$ examinations factors must legitimately evaluated, as substantial correspondence properties of correlations :

$$
\tilde{\mathrm{a}}_{\mathrm{i}, \mathrm{j}}=1 / \tilde{\mathrm{a}}_{\mathrm{i}, \mathrm{j}} \tilde{\mathrm{i}}_{\mathrm{i}, \mathrm{j}}=1 / \tilde{\mathrm{a}}_{\mathrm{i}, \mathrm{j},}, \forall i \neq j
$$

In addition:

$$
\text { ãi,j=1, } \forall i, j=1,2 \ldots, C_{K}
$$

Step 2: Construct the fuzzy evaluation matrix.

Correlations coefficients $\tilde{\mathrm{a}}_{\mathrm{ij}}$ is utilized to develop correlation $\tilde{\mathrm{A}}_{\mathrm{k}}$, corresponding the positive matrix. For the total of different clients decisions, various strategies, max-min. number juggling be around, symmetries whole, t-standard, and accessible. The formalconsiderby way ofcollector operative brought up, it permits the AHP requirement communicated by equation (4). Actually, if $\dot{P}_{\mathrm{ijk}}$ is the fuzzy inclination of the conventional client and $t$ the quantity of decisions to be totaled, it is conceivable to compose:

$$
\tilde{\mathrm{a}}_{\mathrm{i}, \mathrm{j}}=\left(\prod_{k=1}^{\mathrm{t}} \mathrm{P}_{\mathrm{ijk}}\right)^{1 / t} \tilde{\mathrm{a}}_{\mathrm{j}, \mathrm{i}}=\left(\prod_{k=1}^{t} \frac{1}{\mathrm{P}} \dot{\mathrm{ijk}}^{\frac{1}{t}}\right.
$$

also, subsequently :

$$
\tilde{\mathrm{a}}_{\mathrm{i}, \mathrm{j}}=1 / \tilde{\mathrm{a}}_{\mathrm{j}, \mathrm{i}}
$$

In this manner, the pairwise correlation framework for the upper pecking order dimension of the service criteria is built. The following stage is identified with the assessment of the nearby significance loads of the facility sub-principles and principles, by utilizing accompanying computation technique.

Step 3: Compute together the most extreme fuzzy and the connected fuzzy of $\tilde{\mathrm{A}}_{\mathrm{k}}$.

Related fuzzy eigenvector of $\tilde{\lambda}_{\text {max }}$ of $\tilde{\mathrm{A}}_{\mathrm{k}}$ arrangement of the accompanying fuzzy relationship :

$$
\tilde{\mathrm{A}}_{\mathrm{k}} \cdot \widetilde{w}=\tilde{\lambda}_{\max } \cdot \widetilde{w}
$$


In which $\widetilde{w}$ is a fuzzy vector $\left(\mathrm{C}_{\mathrm{k}} \times 1\right)$ of the significance loads of the $\mathrm{C}_{\mathrm{k}}$ looked at sub-principles measured in the matrix $\tilde{A}_{k}$. Since connections revealed in, (2) for the conventional sub-model equation (8) can composed as:

$$
\left.\left\lfloor\left(a_{L}^{a}\right)_{i, 1} \cdot\left(w_{L}^{a}\right)_{1} \cdot\left(a_{U}^{a}\right)_{i, 1} \cdot\left(w_{U}^{a}\right)_{1}\right\rfloor \oplus \ldots \oplus\left(a_{L}^{a}\right)_{i, n} \cdot\left(w_{L}^{a}\right)_{n} \cdot\left(a_{U}^{a}\right)_{i, n} \cdot\left(w_{U}^{a}\right)_{n}\right\rfloor=\left(\lambda_{1}^{a}\right) \cdot\left(w_{L}^{a}\right)_{i} \cdot\left(\lambda_{U}^{a}\right) \quad \cdot\left(w_{U}^{a}\right)_{i}
$$

In which:

$$
\begin{aligned}
& \tilde{\mathrm{A}} \mathrm{k}=[\tilde{\mathrm{ai}}, \mathrm{j}], \widetilde{w}^{t}=\left(\widetilde{w}_{1}, \ldots . \widetilde{w}_{C k}\right), \\
& \tilde{a}_{i j}^{a}=\left[\left(a_{L}^{a}\right)_{i, j},\left(a_{U}^{a}\right)_{i, j}\right] ; \widetilde{w}_{i}^{a}=\left[\left(w_{L}^{a}\right)_{i},\left(w_{U}^{a}\right)_{i}\right] ; \tilde{\lambda}_{\max }^{a}=\left[\left(\lambda_{U}^{a}\right)_{i},\left(\lambda_{L}^{a}\right)_{i}\right] \\
& \forall a \in[0,1] ; i, j=1,2, \ldots ., C_{k}
\end{aligned}
$$

$a(a-$ cut $)$ is identified to incorporate client's certainty above his /her inclinations. For situation in this thought of it as joins the partners' certainty and vulnerability over their decisions. Thusly, by thinking about the list of idealism, the fresh pairwise correlation factor of significance concerning facility sub-principles I and $\mathrm{j}$ certainty neara can composed:

$$
\begin{aligned}
& \tilde{a}_{i j}^{a}=\mu \cdot\left(a_{U}^{a}\right)_{i, j}+(1+\mu) \cdot\left(a_{L}^{a}\right)_{i, j} \\
& \forall a \in[0,1]
\end{aligned}
$$

At the point when an is fixed, in the wake of setting the file of positive thinking 1 the accompanying matrix (12) could be acquired, thus measured to assess the neighborhood significance loads of the reflected facility sub-principles .

$$
\tilde{\mathrm{A}} \mathrm{k}=\left[\begin{array}{cccc}
1 & \tilde{a}_{1,2}^{a} & \ldots & \tilde{a}_{1 n}^{a} \\
\tilde{a}_{2,1}^{a} & 1 & \ldots & \tilde{a}_{2 n}^{a} \\
\ldots & \ldots & \ldots & \ldots \\
\tilde{a}_{n 1}^{a} & \ldots & \ldots & 1
\end{array}\right]
$$

Equations (8)and (10) and (12) compare to the fuzzy function Max strategy, at first presented in fresh AHP strategy[15]

Step 4: Compute the universal significance weight.

The latter advance decides the universal significance loads of the facility sub-principles. The last can be acquired by duplicating the neighborhood significance loads of every facility sub-principles in significance weights or the linked facility rule .

\subsection{Estimation of partners' observations}

Fresh observation identified with the facility sub-principles $\mathrm{i}$ of the nonexclusive facility rule $\mathrm{k}$, certainty level $(a-c u t),\left(\tilde{p}_{a)_{k . i}}\right.$, canacquire with allude to decisions consummation step. The last is assessed by the record of idealism $\mu$. The bigger esteemof the guide $\mu$ demonstrates the higher level of good faith. Such fileis a straight curved mix definite :

$$
\begin{aligned}
& \left(\tilde{p}_{a)_{k . i}}=\mu\left(p_{U}^{a}\right)_{k, i}+\left(1+\mu \cdot\left(p_{L}^{a}\right)_{k, i}\right.\right. \\
& \forall a \in[0,1]
\end{aligned}
$$

in which in equation (13) $\left(p_{U}^{a}\right)_{k, i}$ and . $\left(p_{L}^{a}\right)_{k, i}$ are the greater as well as lesser limits of fuzzy totaled decisions certainty level $a(a-c u t)$ allowing collector operative the calculation average. in wake of setting the record of good faith $\mu$, equation. (13) gives the fresh estimation of clients' recognition for the thought about subcriterion .

a) Quality in Iraqi advanced education zone

The Iraqi community has tended to impressive regard for educational foundations, meanwhile the last shows a basic job in global and national advancement. Educational foundations bolster global advancement techniques by giving the exceedingly qualified labor. Among the diverse dimensions of training, higher training is especially critical to cultivating innovative ability, which is the principle way to improve a country's intensity, the fundamental factor in expanding national quality [23]. In this manner, advanced education greatly affects the advancement of a country's upper hand. An extraordinary number of colleges are experiencing imperative changes so as to build their quality dimension both in instruction . Many studies have additionally affirmed that colleges presently cooperate with an assortment of other learning makers[24], savvy capital has turned out to be significant all together to strengthen colleges' jobs in the new 
economy for the accompanying reasons: right off the bat, colleges' primary information sources and yields are to a great extent impalpable, and just a little bit of them greatly affect the colleges' activity forms ; furthermore, colleges are being compelled to spread more data to partners, for example, understudies, open specialists that support colleges, work markets. To guarantee nature of instructive service, models and methodology have been created with the demonstrative rather than prescriptive reasons. The last methodologies are generally detailed so as to enable their materialness to all of advanced educational organizations and all the Iraqi offices for quality affirmation .

b) University of Kufa degrees instruction facilities performance

The plan at the University of Kufa is described through together, Master and Bachelor Degrees. They manage the arrangement of specialized, financial, administrative and hierarchical issues in the goods/ facilities generation, commercialization forms. The Master Degree guarantees profound methodological abilities for overseeing multifaceted nature, change and advancement the executives so as to permit the improvement of a job that can connect with authorities of the diverse company's capacities and goes about as an integrator of both specialized, not specialized capabilities. The program bargains with an understudies' bowl of around 800 parts, it portrays execution definite advances obligatory by the excellence managing. The vital training facilities investigation along these lines announced to an important advance toward the bearing to be sought after specifically understudies that are primary chauffeurs of persistent development procedure $[15,25]$.

\subsection{Ratediagram of Instruction Facilities}

This planned technique the esteem diagram for below investigation administration must be depicted. Specifically, there is certifiably not a novel and generally acknowledged esteem chain of command conspire for advanced education facilities; such a circumstance features the profound.

Multifaceted nature of instructing, learning and bolster benefits in the scholarly setting in specific, their component has called the attention to by utilizing the Serious Case Method, based off fundamental center gatherings with both facility specialists (leaders gathering). Portrayed facilities rate diagram comprises of four dimensions :the largest amount incorporates the general 4 instruction facilities principles are firmly connected by accounted for :Showing Workforce, Substructures, Utensils and Funding facilities .

\subsection{Poll Construction and Assessment Rules}

The esteem tree announced is measured to build up the poll for the overview. The last is made via two sections; firstly, partners are requested to show general significance examinations of training facilities principles, sub-principles and things. Secondly, partners are approached to evaluate them recognitions connected to training facility things. Together survey sections' partners call attention to dimensions of their decisions by utilizing appropriate fuzzy semantic assessment scales. Table 1 demonstrates the first and the second piece of the created poll identified with the facility sub-paradigm classrooms having a place with the facility rule foundations, for both, the file of good faith 1 and the certainty level $a(a-c u t)$ have been accepted an esteem equivalent to 0.6 and the phoneticfuzzy scales detailed.

Table 1. Concentrate of the embraced questionnaire to assess the facility components identified with the sub-measure Classrooms

\begin{tabular}{|c|c|c|c|c|c|c|c|c|c|c|c|c|c|c|c|}
\hline & & sibi & $\mathrm{O}$ & $\mathrm{vid}$ & ots & Stu & hall & ght & & & Stu & hall & ven & on & olding \\
\hline \multirow[t]{2}{*}{ Study halls acoustic } & $\mathrm{B}$ & $\mathrm{A}$ & \multirow{2}{*}{$=$} & $\mathrm{b}$ & A & $\mathrm{B}$ & $\mathrm{A}$ & \multirow{2}{*}{$=$} & $\mathrm{b}$ & A & $\mathrm{B}$ & $\mathrm{A}$ & \multirow[b]{2}{*}{$=$} & \multirow{2}{*}{$\begin{array}{l}\mathrm{b} \\
\mathrm{d}\end{array}$} & \multirow{2}{*}{$\begin{array}{l}\mathrm{A} \\
\mathrm{C}\end{array}$} \\
\hline & $\mathrm{D}$ & $\mathrm{C}$ & & d & $\mathrm{c}$ & $\mathrm{D}$ & $\mathrm{C}$ & & d & c & $\mathrm{D}$ & $\mathrm{C}$ & & & \\
\hline $\begin{array}{l}\text { Contrasted and } \\
\text { Study halls air } \\
\text { ventilation and } \\
\text { molding }\end{array}$ & B & A & & $\mathrm{b}$ & A & B & A & $=$ & $\mathrm{b}$ & A & $\mathrm{B}$ & A & $=$ & $\mathrm{b}$ & A \\
\hline Study halls lighting & B & A & - & $\mathrm{b}$ & A & B & A & $=$ & $\mathrm{b}$ & A & & & & & \\
\hline
\end{tabular}

\subsection{Results}

The survey has been led for a quarter of a year, between February and May 2019, and around 300 pupils complete total of 21 responsive between facilities leaders, for example the teachers that oversees course exercises, and educators have been met. Only for a precedent, they got collected fuzzy correlation lattice identified with the facility things of the sub-measure Classrooms and the related fresh correlation lattice . Actually, with alluding to the recently thought about facility things, Table 2 reports both the acquired fuzzy amassed estimations of understudies discernments and the related fresh ones. Figure 1 outlines the 
acquired training facilities execution results. Additionally, the affectability investigation is executed by differing together $\mu$ and standard $a(a-c u t)$.

Table 2. Students' desire and recognition levels

\begin{tabular}{|c|c|c|c|c|c|c|c|c|}
\hline Criterion & $\begin{array}{c}\text { Important } \\
\text { weight }\end{array}$ & Subcriterion & $\begin{array}{c}\text { Native } \\
\text { Important } \\
\text { weight }\end{array}$ & $\begin{array}{l}\text { Facility } \\
\text { element }\end{array}$ & $\begin{array}{l}\text { Native } \\
\text { Important } \\
\text { weight }\end{array}$ & $\begin{array}{c}\text { Universal } \\
\text { Important } \\
\text { weight }\end{array}$ & Observation & $\begin{array}{l}\text { Student } \\
\text { fulfillment }\end{array}$ \\
\hline \multirow[t]{9}{*}{$\mathrm{C} 1$} & \multirow[t]{5}{*}{0.644} & \multirow[t]{5}{*}{$\mathrm{SC} 1,1$} & \multirow[t]{5}{*}{0.553} & SI1,1,1 & 0.074 & 0.088 & 0.043 & 0.057 \\
\hline & & & & SI1,1,2 & 0.225 & 0.049 & 0.039 & 0 \\
\hline & & & & SI1,1,3 & 0.37 & 0.075 & 0.032 & -0.033 \\
\hline & & & & SI1,1,4 & 0.14 & 0.033 & 0.045 & 0.022 \\
\hline & & & & SI1,1,5 & 0.187 & 0.042 & 0.035 & 0.003 \\
\hline & \multirow[t]{4}{*}{0.01} & \multirow[t]{4}{*}{$\mathrm{SC} 1,2$} & \multirow[t]{4}{*}{0.467} & SI1,2,1 & 0.064 & 0.076 & 0.03 & 0.042 \\
\hline & & & & SI1,2,2 & 0.098 & 0.026 & 0.039 & 0.023 \\
\hline & & & & SI1,2,3 & 0.549 & 0.107 & 0.049 & -0.048 \\
\hline & & & & SI1,2,4 & 0.192 & 0.043 & 0.043 & 0.01 \\
\hline \multirow[t]{7}{*}{$\mathrm{C} 2$} & \multirow{4}{*}{0.22} & \multirow[t]{4}{*}{$\mathrm{SC} 2,1$} & \multirow{4}{*}{0.699} & $\mathrm{SI} 2,1,1$ & 0.03 & 0.027 & -0.011 & -0.014 \\
\hline & & & & $\mathrm{SI} 2,1,2$ & 0.034 & 0.03 & 0.022 & 0.018 \\
\hline & & & & $\mathrm{SI} 2,1,3$ & 0.036 & 0.025 & 0.024 & 0.013 \\
\hline & & & & $\mathrm{SI} 2,1,4$ & 0.024 & 0.026 & -0.004 & -0.002 \\
\hline & \multirow[t]{3}{*}{0.01} & \multirow[t]{3}{*}{$\mathrm{SC} 2,2$} & \multirow[t]{3}{*}{0.321} & SI2,2,1 & 0.026 & 0.044 & 0.017 & 0.035 \\
\hline & & & & $\mathrm{SI} 2,2,2$ & 0.057 & 0.039 & 0.054 & 0.036 \\
\hline & & & & SI2,2,3 & 0.047 & 0.043 & 0.045 & 0.041 \\
\hline \multirow[t]{13}{*}{ C3 } & \multirow{4}{*}{0.107} & \multirow[t]{4}{*}{$\mathrm{SC} 3,1$} & \multirow[t]{4}{*}{0.326} & $\mathrm{SI} 3,1,1$ & 0.023 & 0.018 & 0.018 & 0.013 \\
\hline & & & & $\mathrm{SI} 3,1,2$ & 0.022 & 0.024 & 0.017 & 0.019 \\
\hline & & & & SI $3,1,3$ & 0.018 & 0.019 & 0.015 & 0.016 \\
\hline & & & & SI $3,1,4$ & 0.017 & 0.017 & 0.01 & 0.01 \\
\hline & \multirow[t]{3}{*}{0.01} & \multirow[t]{3}{*}{$\mathrm{SC} 3,2$} & \multirow[t]{3}{*}{0.441} & SI3,2,1 & 0.033 & 0.032 & -0.026 & -0.027 \\
\hline & & & & $\mathrm{SI} 3,2,2$ & 0.022 & 0.021 & -0.047 & -0.048 \\
\hline & & & & SI $3,2,3$ & 0.018 & 0.022 & -0.051 & -0.047 \\
\hline & \multirow[t]{3}{*}{0.01} & \multirow[t]{3}{*}{$\mathrm{SC} 3,3$} & \multirow[t]{3}{*}{0.137} & SI3,3,1 & 0.023 & 0.025 & 0.001 & 0.003 \\
\hline & & & & SI $3,3,2$ & 0.027 & 0.025 & $-1 E-03$ & -0.003 \\
\hline & & & & SI $3,3,3$ & 0.023 & 0.02 & 0.013 & 0.01 \\
\hline & \multirow[t]{3}{*}{0.01} & \multirow[t]{3}{*}{$\mathrm{SC} 3,4$} & 0.137 & $\mathrm{SI} 3,4,1$ & 0.026 & 0.019 & $-1 E-03$ & -0.008 \\
\hline & & & & $\mathrm{SI} 3,4,2$ & 0.024 & 0.025 & 0 & 0.001 \\
\hline & & & & $\mathrm{SI} 3,4,3$ & 0.022 & 0.025 & 0.014 & 0.017 \\
\hline $\mathrm{C} 4$ & 0.069 & $\mathrm{SC} 4,1$ & 0.884 & SI $4,1,1$ & 0.023 & 0.046 & -0.002 & 0.021 \\
\hline & & & & SI $4,1,2$ & 0.034 & 0.05 & 0.011 & 0.027 \\
\hline & & & & SI $4,1,3$ & 0.058 & 0.08 & 0.019 & 0.041 \\
\hline & & & & SI $4,1,4$ & 0.026 & 0.028 & 0.006 & 0.008 \\
\hline & 0.01 & $\mathrm{SC} 4,2$ & 0.137 & SI $4,2,1$ & 0.022 & 0.044 & 0.009 & 0.031 \\
\hline & & & & SI4,2,2 & 0.031 & 0.046 & -0.008 & 0.007 \\
\hline & & & & SI $4,2,3$ & 0.034 & 0.052 & -0.006 & 0.012 \\
\hline
\end{tabular}

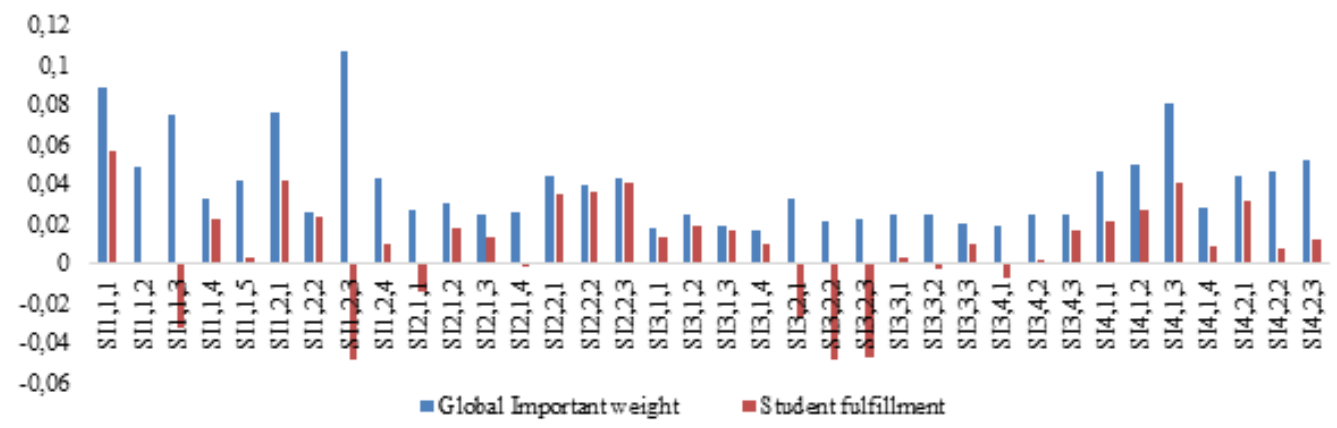

Figure 1. Global important weights and level of services elements

\section{CONCLUSIONS}

In the present paper, a technique has been created that is ready to adequately deal with vulnerability identified with service execution examinations dependent on partners 'decisions. Such strategy is fixated on ingoing improvement of the ServQual inconsistency worldview and utilizes in consolidated way AHP and the Fuzzy Sets Theory. The utilization of such technique has been appeared in vital training services execution investigation identified with the Management Designing system of the University of Kufa. From such 
examination, the service principle Holes have been assessed and appropriate "Holes arranged" system for the general service quality improvement that has been distinguished. Additionally, the impacts of the disparities between understudies' desires and the board's impression of facility superiority (Hole1) and understudies' desires also educators' view of facility superiority (Hole6) on the understudy fulfillment level (Hole5) have been examined and measured by methods for a relapse demonstrate. The permits appropriate outcomes assessments of service execution related exercises performed by both service chiefs and educators . Future examinations concerning training services execution investigations will include further improvements of planned technique by allowing for the Fuzzy Logic method

\section{REFERENCES}

[1] Y.-C. Chou, H.-Y. Yen, V. T. Dang, and C.-C. Sun, "Assessing the Human Resource in Science and Technology for Asian Countries: Application of Fuzzy AHP and Fuzzy TOPSIS," Symmetry, vol. 11, p. 251, 2019.

[2] R. K. Goyal, S. Kaushal, and A. K. Sangaiah, "The utility based non-linear fuzzy AHP optimization model for network selection in heterogeneous wireless networks," Applied Soft Computing, vol. 67, pp. 800-811, 2018.

[3] R. Ammigan and E. Jones, "Improving the student experience: Learning from a comparative study of international student satisfaction," Journal of Studies in International Education, vol. 22, pp. 283-301, 2018.

[4] H.-J. Zimmermann, Fuzzy set theory—and its applications: Springer Science \& Business Media, 2011.

[5] A. J. Ali, Z. Farej, and N. Sultan, "Performance evaluation of a hybrid fuzzy logic controller based on genetic algorithm for three phase induction motor drive," International Journal of Power Electronics and Drive Systems (IJPEDS), vol. 10, p. 117, 2019.

[6] V. Vishwakarma, C. P. Garg, and M. K. Barua, "Modelling the barriers of Indian pharmaceutical supply chain using fuzzy AHP," International Journal of Operational Research, vol. 34, pp. 240-268, 2019.

[7] R. M. G. Kumar, T. Jothimurugan, and P. Anbuoli, "Importance of SERVQUAL dimensions in leveraging service quality in insurance industry from the perspective of different cultural and socioeconomic environment-a SEM approach," International Journal of Services and Operations Management, vol. 30, pp. 98-119, 2018.

[8] Z. Kovacic and S. Bogdan, Fuzzy controller design: theory and applications: CRC press, 2018.

[9] A. H. Ahmed, B. Abd El Samie, and A. M. Ali, "Comparison between Fuzzy Logic and PI Control for the Speed of BLDC Motor," International Journal of Power Electronics and Drive Systems (IJPEDS), vol. 9, p. 1116, 2018.

[10] T. Kim, E. Sotirova, A. Shannon, V. Atanassova, K. Atanassov, and L.-C. Jang, "Interval valued intuitionistic fuzzy evaluations for analysis of a student's knowledge in university e-learning courses," International Journal of Fuzzy Logic and Intelligent Systems, vol. 18, pp. 190-195, 2018.

[11] T. L. Saaty, "Decision making with the analytic hierarchy process," International journal of services sciences, vol. 1, pp. 83-98, 2008.

[12] H. Attia, "Fuzzy Logic Controller Effectiveness Evaluation through Comparative Memberships for Photovoltaic Maximum Power Point Tracking Function," International Journal of Power Electronics and Drive Systems(IJPEDS), vol. 9, p. 1147, 2018.

[13] T. Lupo, "Strategic analysis of transit service quality using fuzzy AHP methodology," European Transport Trasporti Europei . April 2013.

[14] I. Waleed, A. Baha, and M. Ali, "Voltage Tracking Control of DC-DC Boost Converter Using Fuzzy Neural Network," Int. J. Power Electron. Drive Syst (IJPEDS), vol. 9, pp. 1657-1665, 2018.

[15] P. Sultan and H. Yin Wong, "Antecedents and consequences of service quality in a higher education context: a qualitative research approach," Quality assurance in education, vol. 21, pp. 70-95, 2013.

[16] B.-Y. Cao and Y.-B. Zhong, Fuzzy Sets and Operations Research: Springer, 2019.

[17] D. Napitupulu, R. Rahim, D. Abdullah, M. I. Setiawan, L. A. Abdillah, A. S. Ahmar, et al., "Analysis of student satisfaction toward quality of service facility," in Journal of Physics: Conference Series, 2018, p. 012019.

[18] A. Vaz and S. Mansori, "Malaysian private education quality: Application of SERVQUAL model," International Education Studies, vol. 6, pp. 164-170, 2013.

[19] F. Olivas, F. Valdez, P. Melin, A. Sombra, and O. Castillo, "Interval type-2 fuzzy logic for dynamic parameter adaptation in a modified gravitational search algorithm," Information Sciences, vol. 476, pp. 159-175, 2019.

[20] A. Geramian, A. Shahin, B. Minaei, and J. Antony, "Enhanced FMEA: An integrative approach of fuzzy logicbased FMEA and collective process capability analysis," Journal of the Operational Research Society, pp. 1-13, 2019.

[21] A. B. McBratney and I. O. Odeh, "Application of fuzzy sets in soil science: fuzzy logic, fuzzy measurements and fuzzy decisions," Geoderma, vol. 77, pp. 85-113, 1997.

[22] S. A. Abdalmenem, R. O. Owda, A. A. Al-Hila, S. S. Abu Naser, and M. J. Al Shobaki, "The Performance Efficiency of University Education between Reality and Expectations," International Journal of Academic Management Science Research (IJAMSR), vol. 2, pp. 66-76, 2018.

[23] K. Kumpulainen and T. Lankinen, "Striving for educational equity and excellence: Evaluation and assessment in Finnish basic education," in Miracle of education, ed: Brill Sense, 2016, pp. 69-82.

[24] O. Castillo and K. Atanassov, "Comments on fuzzy sets, interval type-2 fuzzy sets, general type-2 fuzzy sets and intuitionistic fuzzy sets," in Recent Advances in Intuitionistic Fuzzy Logic Systems, ed: Springer, 2019, pp. 35-43.

[25] J. C. R. Alcantud and V. Torra, "Decomposition theorems and extension principles for hesitant fuzzy sets," Information Fusion, vol. 41, pp. 48-56, 2018. 